\title{
A Discussion of Kretchmar's Elements of Competition
}

\author{
Richard Royce
}

\section{Introduction}

In a recent journal Kretchmar [2014] attempted to apply and explore Husserl's transcendental phenomenological method in relation to clarifying, in the context of sport particularly, "if hard and fast claims about the nature of competition were even possible" [2014, 35]. With respect to both method and results his conclusions were less than enthusiastic. In a post-script he claimed "I confess to feeling, even at this point, that I barely broached the subject" [2014, 35] and as to methods, "There seems to be a degree of sterility to this kind of analysis" [ibid]. Despite this he reports as findings "the more essential competitive wall conditions" [2014, 35] even if there is additional work to be completed. My concerns here have a different ambition, and as my endnotes indicate, also challenge those who share some conclusions reached by Kretchmar. My focus is solely upon the results of the inquiry with respect to gaining an understanding of competition. Perhaps given a wider brief I would share Kretchmar's reluctance to fully endorse the chosen method and after my inquiries might have found myself agreeing with him when he claimed, "so much more could have been reflected on. So many more variations might have provided additional or even contrary illuminations" [ibid]. It is then no criticism of Kretchmar's effort when I claim below to unearth some of these 'contrary illuminations': in writing later I have the benefit to take the discussion further. On the assumption then that the method used was appropriate and the analysis on the right lines, Kretchmar's conclusions which I now consider are that "the elimination of any one of these elements - plurality, comparison, normativity, or disputation - renders competition unintelligible" $[2014,27]^{1}$. Each element will be elaborated upon in turn below. I show, in passing, that the ground is well-trodden and that others have produced comparable findings. It would indeed be strange if they were radically different. Less recently, however, alternative conceptions have been considered [e.g. Skultety 2011; Royce 2013], but matters remain contentious [Skultety 2015].

Before examining closely the relation of these four elements to competition it is helpful to distinguish some uses of 'competition' in order to clarify contexts for testing applications of them. An important difference is that between reference to competition as what I shall call an institution, and when we use 'competition' to refer to the act of taking part in a competition. The institutional sense relates to the terms and conditions of a competition including those specifying how applicants qualify as entrants; rules regulating behaviour of competitors; conditions governing disqualification and award of any prizes; the basis on which winners and losers will be identified, and so on. When we refer to competition in this institutional sense we are referring to what may be written down and what precedes the competition getting under way. When we say that someone is in a competition it is appropriate to be asked which one, and indicating the institutional details is one way to respond. 
On other occasions, however, we remark that someone is [was or will be] in competition with another and in this use one thing we may mean is that she is [was or will be] taking part in a competition. Call this, for want of a better label, the participatory sense ${ }^{2}$. Supplying information contained by use of the institutional sense can clarify which competition someone is in: but it is not always available. For example, we might refer to people being in competition with each other without there being any clarified and agreed terms and conditions of a competition. Siblings or neighbours might see themselves and be seen to be in competition with each other, outside of any terms and conditions governing their competitive behaviour. They act competitively towards the other in selected, evolving and valued ways. So people can be in competition [participatory sense] against each other without being in a competition [institutional sense] with each other. The absence of the institutional sense of competition here is not because terms and conditions of their competing are not written down but could be. It is because there are no defined conditions providing an agreed framework for their competing, with a clear start and conclusion, regulations delimiting the focus of application, rules specifying who may compete, clarification on disqualifications, and so on. The participants themselves might be unaware of when they first began to act competitively or when the other did; how spheres of competitive activity arose or dissolved; or why they behave in the ways they do with regard to some but not towards all others. They might also be unaware of how competitive their behaviour is with respect to each other.

\section{The first ${ }^{3}$ element - plurality}

With the addition of a few more observations these points can help exploration of the relation to competition itself of the elements Kretchmar discusses. Starting with the institutional sense we can imagine a competition being set up. Terms and conditions are clarified and include rules governing entry to the competition. These latter require, for example, self-registration by those wishing to enter the competition and who are also members of a school, town, between certain ages, or of a particular sex, and so on. To permit entries the competition registration list is displayed in the school corridor, on the club website, etc. Finally, we should note that in discussing the four elements just listed Kretchmar uses the words 'contest' and 'competition' interchangeably: "...the nature of competition, agon, or contest, as it is variously identified" [2014, 21]. What, then, are consequences of reference to this institutional sense of competition, that is, to being in $a$ competition, for Kretchmar's claims concerning the elements? Consider first his claims about the element of plurality, without which competition is said to become unintelligible ${ }^{4}$. He says "...competition is grounded in plurality. Competition, in other words, does not work in isolation - that is, in the absence of at least some identifiable other" [2014, 23]. Large numbers of competitors pose no theoretical problem for competition, but with less than "two parties, two acts and two products, we lose competition" [2014, 24]. In short, "a contest against nobody ...makes no sense" [Kretchmar 2014, 24]. But these comments do not apply to the institutional sense of competition, for the following reason. Competitions in 
the institutional sense have no entrants when first set up. Creating a competition must precede entering it. Hence, it can have any number of entrants from zero to the maximum permitted. Rules might state that the competition [institutional sense] will be declared null and void unless two [or any stipulated number of] entrants join, but need not specify any minimum number. A competition, then, might remain with no entrants, or attract one only. Because this is intelligible, claims to the contrary have weaknesses. Plurality is not a required element of competition in the sense discussed here.

What then of using 'competition' to refer to the event itself in operation, to taking part in a competition, to being in competition in the participatory sense? Is plurality a requirement of competition here? Suppose, in the institutional sense of competition considered above, that by the time entrance to the competition closes it has only one entrant; that nothing in the terms and conditions specifies a minimum number of entrants required; that winning the competition consists of more than merely entering it. The competition organizers are not going to award first place in the running event to someone who can't run; or in the pole vault to someone who cannot vault with a pole. So, the sole entrant has to perform the event to win it. We can imagine similar requirements for winning the pie-baking, flower arrangement, discus, and other competitions where taking part is not dependent upon the 'opposition' showing up. No doubt the tennis competition will have different procedures. But what this demonstrates is that it is not just the institutional sense of competition which is intelligible without a plurality of entrants, but the taking part sense which is too. Our sole athlete met the entry terms and conditions of the competition [institutional sense] and completed in a faster time or with a higher vault the task identified distinguishing this competitive event from any others. Of course, the event might have been the last heat to be run and where none of the others expected to take part appeared: they had been injured in other events. Still our sole participant, but in this case not sole entrant in the heat would go through to the next round, perhaps to the final. He is in the competition, and his being the sole runner in his competitive heat, and its being a competition, are far from unintelligible.

This situation should not be seen as bizarre or ineffective. For example, as an incentive huge sums of money might be available as the prize in a competition to best solve a problem whose unattended continuation would have world-shattering consequences. Only one person manages to produce a solution despite attempts by thousands attracted by the prize to work towards finding an answer to the problem. The latter, however, recognise their inability to solve it, and so only one person enters the competition. She wins the prize, the competition was effective, a solution found. Certainly, our winner might have been the sole entrant and not won the prize: more was needed than entering and taking part in the competition. A solution to the world threat had to be submitted to satisfy a further condition of the competition. However, the sole entrant was not denied the prize on the grounds that no one else registered for and took part in the competition. That would be self-defeating of the organisers. Awarding her the prize recognises that she alone satisfied 
conditions governing entry to the competition and success in it. Plurality, therefore, is not a requirement of the intelligibility of either of the two senses of competition discussed here.

Consider a further point and my reply to it. An objection is that while the prize winner mentioned above entered a competition she did not compete in it, on the grounds that there was no opposition, or as it is sometimes expressed, 'no competition'. Against this, first, competitions vary and with some of them no entrants know how many others have also entered, but such lack of knowledge need not influence how hard they try to win, nor how competitively they strive. This can also be the situation when there is only one entrant who knows she is the only one. Second, our entrant would not win the prize on the grounds of being the sole entrant. In this example, at least a plausible solution to the problem advertised had to be submitted. The competitive aspect occurred in isolation when trying to devise a solution to the task. In sport one can imagine a competition in which all athletes have to run the same set distance as fast as they can, on their own, without knowing how many or even whether any others are in the same competition, and what their results are. This is still an institutional competition in which one or more athletes compete. Third, in a very unevenly matched competition where one entrant is superior to all others and when we might say 'there is no competition' for him, he still has to put some effort to winning and compete sufficiently to win. Entrants do not refrain from competing when they are exerting less than maximum effort. Runners in heats are often seen to compete enough to qualify for the final without pushing themselves to the limit.

Suppose it is countered that Kretchmar's discussion is intended to apply only to a sense of competition which he equates to contesting, and that this latter is partly defined by the plurality of its participants. In several places and in more than one article he implicitly or explicitly indicates that he uses the words 'contest' and 'competition' and 'agon' interchangeably ${ }^{5}$. But note too reasons to doubt whether his practice of using the terms interchangeably requires them to relate only to the plurality he highlights. Early on he reminds us [2014, 23-24] that "those who contest...try to put two or more things side by side...for purposes of evaluating their similarities and differences" and the environments in question may be debates, bake-offs, tractor pulls, and essays. His starting point is therefore to establish that competition requires comparison of these 'two or more things'. It is then not difficult for him to move us to the next step and "suggest that competition is grounded in plurality" [2014, 23], a necessary condition for making a comparison. But this is a step backwards. Before we can establish that comparison is needed, we must check that plurality obtains, or there might not be anything to compare with anything else. That two or more things are being compared, however, is insufficient to establish the conclusion Kretchmar wants to attain. He does not want as his conclusion that competition requires a plurality of objects: what he wants is that there must be a plurality of competitors. Hence, when I arrange a number of my baked goods in the village home-cooking competition we have a plurality of pies and cakes submitted for comparison, but only one competitor - me. He starts by discussing a comparison of objects [2014, 23] before considering the number of 
golfers competing [2014, 24], as he moves to do when discussing plurality, and this not only reverses the order needed but also muddles the number of objects of comparison with the number of competitors needed. In short, from the fact that in making comparisons we need a number of things to compare we should not conclude that we also need a number of people to make the comparisons. This is what he implicitly does later when summarising earlier claims:

Contesting includes a disputation, an argument, a commitment by two or more parties to show superiority over the other(s)... Without a bilateral or multilateral dispute, there can be no contest [2014, 26].

And if we are to assume all along that the only sense of competition we are discussing is one where several people are involved as competitors, we don't need arguments to establish this: we simply declare our assumption.

\section{The second element - comparison}

Given competition in the two senses outlined here [institutional and participatory] is intelligible without requiring the element of plurality, what are implications for the element to which it is said to relate closely, namely 'comparison'? Recalling the interchangeability of 'contest' and 'competition', note what Kretchmar maintained: "...contesting acts, if nothing else, require comparison" [2014, 23]. We cannot compare one thing, simpliciter. We need at least two to make a comparison. He maintains "...a contested comparison with nothing...makes no sense" [Kretchmar 2014, 24]. However, his insistence here concerning comparison as an element is brought into doubt by earlier claims when he stated that the contested world "is one in which comparisons can be made" [p. 23, my emphasis] and he gives examples which he believes "allow us to juxtapose one thing to another and evaluate their differences" [p. 23, again my emphasis]. In competition are we required to make comparisons, or does it merely permit them [on some occasions] to be made? If the claim relates only to possibility, then failing to take advantage of the opportunity hardly renders the context unintelligible as a competition. But to be consistent with his other claims, Kretchmar must be understood to mean that with competition, comparisons are always possible, because competition always involves plurality; and that in addition, we must compare because "contesting acts...require comparison" [2014, 23].

However, if the claim that competition requires plurality is defeated, then will the conclusion that competition requires comparison also fall? Where there is only one entrant to a competition, and where only one entrant is submitting himself to the terms of the competition, we have no other entrant with whom he must be compared. Suppose it is replied that our one entrant's achievement in competition can always be compared to the prior achievements of another in the same activity, whether or not the latter's results were in a competition. In reply, that cannot be used to defend the claim that comparison is a required element of competition, because our one entrant might have attempted 
something not known to have been or not previously attempted by anyone, and hence where there is no direct comparison to be made. Further, the cost of attempting to defend in this way comparison as an element of competition is to deny that plurality is an element. If competition requires that we must make a comparison and that in cases of a sole entrant to a competition that will be with someone's effort outside of the competition, it implies competition can have one entrant / performer alone, and that plurality is not a required element of competition. While someone performing later an act previously performed by many others might have as an aim to achieve better than all previous efforts, this does not require us to classify all the earlier performers as being in a competition, or that all previous performances were undertaken competitively. It is not plausible to maintain that anyone's later achievements undertaken with a competitive intention require us to re-classify others' previous efforts at the same activity as attempts to set an unsurpassable standard of achievement when they completed their performance in, for example, mundane acts such as sweeping the floor quickly. Someone's sporting achievement might be hailed as the best ever when compared with that of others in the same activity, but comparison itself does not imply any of them were competing against each other, in a competition, or for a prize.

There are other difficulties with asserting comparison is required for competition, especially in the context that comparison can occur irrespective of whether there is competition. Conditions prior to events might be compared to ensure that in relevant respects they are the same, for example by measuring tail wind speed before a running event. But comparisons of completed performances must follow performance itself, implying at least one important aspect of comparison can occur only after the competition has finished. At least this holds for many simultaneous competition action sports such as running events; several team games; swimming; and motor racing. In what sense then can it be maintained that comparison is a condition of competition rather than contingent on it? Is it unintelligible to state that before, during and after competitive performances were completed comparisons were not made? After the football match, everyone was silent and hurried off home. Must I state, or must the thought enter my consciousness after playing tennis, 'so you won'? Is this the sort of comparison which is said to be required by competition, and without which competition is said to be unintelligible? Or is it more plausible to imagine a scratch, time-regulated game where no one has kept score throughout the match but all know when it is over, and no comparisons are made? Is it players, officials, spectators or a combination of them who must make comparisons in order to elevate events into a competition? And if so, what must be compared - individual or team performance; or event results; or use of skills; or of game tactics; and so on? Games such as soccer, tennis, hockey and cricket are competitive enterprises. But we know this ahead of noting whether any comparisons are made between players or teams taking part, or between points and scores achieved. If during play and the post-match scenario no comparisons are made, we do not retract our claim that a competition was taking place. We do not await the first comparative thought or comment to have confirmed that we are 
watching a competitive event. Someone exclaiming of two grandmothers knitting side-byside, each notorious for claiming she knits faster than the other, that one is progressing more rapidly does not transform the simultaneous practice of their hobbies into a competition. So, here too, comparison is simply an optional activity and not a requirement [along with other elements] of competition.

Kretchmar's insistence that competition is reciprocal, placing emphasis on competition against or with others, overlooks the idea of competition as an attempt in some circumstances to achieve a goal independent of others. Certainly the sole competitor must satisfy conditions of the competition and may compete for the prize, or to demonstrate better personal performance.

\section{The third element - normativity}

The third element is the normative one, referred to as evaluative comparison, and hence links to the second element. Kretchmar summarises this referring to "...contests as evaluated comparisons...Competition, in short, becomes unthinkable in the absence of the normative element" $[2014,25]^{6}$. In sport, competition may produce winners and losers, and even if draws result, this seems consistent with the presupposition of a normative element, that is, of contestants being compared with respect to their relative quality in the activity. Judgements here are said to relate to what is better or worse; superior or inferior; stronger or weaker ${ }^{7}$. But what might more detailed analysis reveal? Precisely what is being claimed by stating competition must have a normative element?

Kretchmar's position is that "Competitive comparisons...require... judgments about relative worth" [2014, 25]. The defence given to this position is brief and limited, however. We are told that without it contests would make no sense. Kretchmar [ibid] even claims that "philosophic debates would be reduced to simple conversations" without evaluative comparisons of ideas, logic, and evidence. Given the context in which he uses this as an example, he assumes the debates, and philosophic discussion itself, are competitive enterprises rather than exploratory and investigatory ones. First, leaving aside doubts above about whether any comparisons at all are required in competition [and I have argued they are not], what can be said about evaluative as distinct from descriptive comparisons? Kretchmar's test of intelligibility is not met in examples of competition where descriptive differences suffice to identify winners and losers. A competition to grow the longest carrot, the heaviest squash, the largest beetroot, or the biggest bunch of grapes is, whatever shortcomings one might attribute to such an enterprise, perfectly intelligible. Targets in each case can be provided in clear, measurable, descriptive terms. Moreover, there is no obligation to equate the biggest dimensions with best quality food, nor to believe the relative worth of each class of vegetable is related to its size. Taste, freshness, appearance and nutritional content are all contenders for quality. 
Elsewhere Kretchmar elaborated with "sport is structured to produce a comparison, a ranking, a 'better than' and 'worse than' kind of conclusion", [2012, 104] but he also noted a paradox too when adding "Those who are more skilled or virtuous should also perform better. Those who have lesser capabilities should perform worse. But in sport, that is not always the way things turn out" $[2012,110]$. Hence there is acknowledgement that we can recognise a winner and losers without respectively identifying them as superior and inferior sportspersons. Assignation of the winning and losing position following a sport competition is a descriptive act: not an evaluative one ${ }^{8}$. We are not constrained by reasons of necessity to draw from the score-line of the match any evaluative conclusions concerning comparisons of players' abilities or levels of performance, and the 'is-ought' distinction, if there is one [see, for example Hudson, 1969, but also much later debate, for example Hindriks, 2012] gives support to this. Competition is thus eminently 'thinkable' in the absence of any normative element, as those following the argument here can testify.

The availability of objective criteria on the basis of which sport competition outcomes rest is equally apparent. Competitions reveal who can run fastest, throw farthest, jump highest, and score more points, goals and runs. Those who do are the winners. Comparisons here too are with descriptive data. A further step is needed if we want to equate 'more', 'faster', or 'further' with 'better'. The idea that such competitions make no sense when devoid of evaluative comparisons is thus readily refuted. But in Kretchmar's claims it is possible to discern a different thesis which emphasises not assessment by outcome but evaluation of process. Two examples illustrate this. Concerning a competitive chess match the issue is presented as "which set of moves is more successful in terms of the purposes and requirements of the game", while in pie baking contests the measure is said to be the culinary skills [2014, 25]. However, the set of chess moves and the culinary skills are no more than means to ends, and it is the latter which are typically taken as criteria for victory in the respective competitions. One can devise competitions where typical means to other ends are judged independently of the ends they customarily attain, or even before the usual ends are attained. Perhaps running on an athletics track one hundred metres faster than others, and not on a football or rugby pitch where it would be useful, is an example. But then, out of the game and in a different competition it is no longer a means to another end, but in need itself of criteria for judging victory. Similarly, while some moves in chess are better than others with respect to achieving a win, the competition is decided by the objective state of affairs, the checkmate, irrespective of which legitimate means are employed to attain it. In any case, in sports the match or event result given in descriptive terms is invariably a good indication of more successful means to achieving the result. The numerical [non-evaluative] data are decisive. Thus competition is highly intelligible without making evaluative comparisons, and as argued earlier, without making any comparisons at all ${ }^{9}$.

Against these arguments can it be contended that too much has been read into the concept of normativity when it is identified as an element of competition? Perhaps all that is 
meant is that whichever test is set in the competition should be seen as the standard of quality. Where the winner will be the person who runs the distance the fastest, fast running is taken to be better, the fastest runner to be superior, and speed of running judged as meritorious. Hence when after the event we rank the runners in their order of finishing, we ipso facto rank their relative worth as runners over the distance run. If this were so the response faces the following difficulties. First, what we compare is still something descriptive in origin: the times taken, the distances thrown, the heights jumped. We cannot independently of these descriptive comparisons make the claimed evaluative comparisons. So far it might appear Kretchmar [2014, 25] would agree: "while competition requires comparison and assumes a descriptive identification of the things to be compared, it requires more." But closer inspection reveals that for him 'descriptive identification' relates to clarifying differences between disparate entities such as a chair and a sunset; football and basketball; sweet and sour desserts. Such comparisons are what he means by simple or descriptive ones. He seems to assume that in some way competition transforms a descriptive comparison into an evaluative one. Of these athletes some have fair hair and others dark; some are over six feet tall but 2 are not; one is wearing a yellow T-shirt [and so on - descriptive comparisons]. But if we state this runner ran in under 9.3 seconds whereas another did it in 9.2 seconds; she jumped eighteen feet and the other one another six inches, and so on, we are making evaluative comparisons. If so presumably we could reverse the categorisation of criteria of comparison by correctly point out that the running had nothing to do with it. In fact, the athlete who finished fourth won the competition which was about appearing in the most brightly coloured T-shirt. Our identification of this runner appearing in yellow is now our 'evaluative comparison': not of who ran the distance in the shortest time [a simple description]. A question now is how this transformation has occurred, for nothing descriptive has changed whether the competition is about running or about T-shirts. Some competitions in sport or elsewhere embody evaluative standards [of beauty, grace, or charm], but many are decided by a basic counting or measurement, and hence normative comparisons are not a feature of all, and competition as such intelligible without them. Certainly those who see no point in, for example, a game of soccer, and value neither its ends nor the skills demonstrated in means to achieve them, nevertheless acknowledge such matches as competition. Competition is intelligible as a notion to both those denying and to those recognising the supposed normative element of it ${ }^{10}$.

\section{The fourth element - disputation}

In his attempt to search for elements which capture "all the central features of competition" [2014, 25, my emphasis] Kretchmar next explores the addition of contests being disputes. In a first attempt he [2014, 26] writes, "Contesting includes a disputation, an argument, a commitment by two or more parties to show superiority over the other[s]". Without disputation, people could make evaluative comparisons of athletes' performances, suggesting who the better player is, but do so outside of a contest. Even were the evaluations to take place by players during a match, Kretchmar produces an example 
designed to be rejected as a case of competition. He asks us to imagine a very able chessplaying mother attempting to teach her child as they play each other. She does not play to show superiority over her daughter: she wants to assist her in making better chess moves, and does so following evaluations during the child's play. The child wants to win, but the mother's motivation is to help and not to show superiority over her daughter. Hence, when "This very commitment is missing in the mother's approach to playing chess with her daughter" [2014, 26] it is the mother's intentions which prevent a case of competition because they "lack some element that is essential to competition" [ibid.] It is said to be the fourth, disputation element which is missing when "mother and daughter are involved in two different projects - one pedagogical, the other competitive" [2014, ibid.].

However, there is not total clarity here, which can be seen when precision is requested. Is the fourth element required for competition a particular dispute between participants; or is it that all participants must share the same [conflicting] commitment ${ }^{11}$ to show superiority? Would competition obtain if no participant has disputed ${ }^{12}$ with the others who is superior ${ }^{13}$, but all had entered an event committed to showing superiority with respect to the others? Such a possibility might obtain, for example, in an athletics race at school with pupils assigned by teachers to a particular event, and no dispute previously occurring among the pupils, all of whom are determined to come first in the race. In other words, are there three alternatives governing application of the fourth element, namely dispute, argument or commitment: or did Kretchmar intend three ways to express one criterion here? If on its own, 'commitment to show superiority' is sufficient, then dispute is not needed, at least not in the sense that it is knowledge shared among participants. If all participants had independently and secretly informed a third party of their intention to show superiority we might still doubt this is a dispute. We can regard it as a case of holding conflicting intentions.

But suppose 'dispute' is needed as a condition, and references to argument and commitment are no more than alternative ways of expressing it. How then should dispute be understood? One account is that dispute occurs when "competitors lay claim to an outcome that only one of them will be able to possess" [2014, 27]. Because in some events a draw, tie, or shared victory is possible, these must be excluded from what competitors are laying claim to. What all must contest is undisputed and unshared victory. But this poses a problem for the account because it is common knowledge that many contestants realise their chance of outright victory is non-existent. If, as a condition of their being in a competition, all participants must lay claim to outright victory, many events we regularly regard as competitions can no longer be seen as such. Kretchmar is not attempting a revisionary account of competition. An endnote recognises that some competitors have "little or no chance to show superiority" [2014, 36]. So Kretchmar in an apparent attempt to plug this gap re-words the condition for the disputation element as "contestation makes sense only if both parties 'argue' for success in the direction of superiority" [2014, 27]. Now effort is said to be aimed to "narrow the difference" [2014, 36] between their previous 
achievement and that of the expected and eventual winner. Whether dispute occurs when the argument for success in the direction of superiority is not contested, when for example the expected winner agrees that a contestant might well narrow the gap while still not winning, is not made clear.

But the account is now seen to move from one difficulty to others. Where an overmatched competitor is aiming to narrow the difference between his performance and that of the expected winner, it is unlikely to be an intent shared by whoever is expected to be the winner. As a result, while the idea of 'narrowing the difference' must be seen as a replacement intention for those with no hope of showing superiority, in the context of discussing the fourth element of competition it is an addition to the account we are considering. That is, Kretchmar's condition for evaluative comparison relates to both the intent to show superiority and to narrowing the gap. But a conclusion now is that such socalled competitors are "involved in two different projects"; one competitor tries to show superiority, the other to narrow the gap. As a result, both 'competitors' can gain their intended outcome: the winner to show superiority by winning, and the runner-up to narrow the gap between her result and that of the winner. Therefore the 'dispute' seems to have been removed. There is no one cherished outcome which only one 'competitor' will be able to possess. And if we reflect on Kretchmar's chess playing / teaching example, it appears strange that he went on from that to modify his condition governing a dispute. This is because we can attribute to the two chess players the diverse aims behind the modified account. Here though, it is the mother [the stronger of the two players] who through her teaching wishes to 'narrow the gap' between her chess-playing ability and that of her child, while the daughter [the weaker player], we are told, is playing to win. So Kretchmar's rejection of the mother-daughter game as competition is still on good grounds whether we use his stronger [commitment to show superiority] or weaker additional [trying to narrow the gap] condition of the disputation element. His initial account of the chess players instructed us to reject it as competition because players did not share commitment to a common outcome; his subsequent modification permits players to hold commitments to different outcomes, and hence is in breach of his own conditions for identifying a dispute. In his own words, "Competition is no longer intelligible" when "the bi- or multi-lateral dispute over superiority has been removed from the activity" [2014, 27].

Two other difficulties arise here. First, while a dispute centred on who is superior in an event is properly characterised as one involving an evaluative comparison, argument above not only demonstrated that with one competitor aiming instead to narrow the gap no dispute arises, but also that the replacement intent may not be based on evaluation. What the weaker competitor aims to achieve is often presented in descriptive terms. If there should be any dispute over whether he was successful, the matter is resolvable by inspecting after the event whether the gap has been narrowed. This can be achieved by comparing times, scores, distances, strokes and the like. Here, no evaluations need arise. Introducing the 'narrowing the gap' condition has therefore removed any evaluative 
comparison in some cases. Second, Kretchmar modifies the earlier claim that normativity is an element of competition when he concludes that "it is intended to produce normative evaluations of better and worse" [2014, 27, my emphasis]. So one question is whether normativity is essential for competition, or whether it is sufficient if one merely intends such an outcome even though in some circumstances it does not result. Further, can a competition be set up to include people who have no such intention? Are 'competitions' to exhibit and compare vegetables in terms of their size, weight, length etc., and award prizes to their growers on the basis of these characteristics, improperly called competitions? Are sports 'competitions' which determine outcomes by means of descriptive features of performances properly categorised as competitions? If not, is Kretchmar mistaken in his claim to have identified four elements of competition, and do his conclusions imply a revision to our language?

We have seen then that whether the intention was to produce three grounds for identifying another element of competition - disputation, argument, commitment to show superiority - or whether these are intended to express one and the same condition, there must be doubt about success of the project. Further, modifying the conditions governing dispute to include 'narrowing the gap' produces additional difficulties.

Nothing above denies the psychological possibility that competition can involve several competitors who compete in an attempt to show their superiority over others, but it argues against the strong thesis that competition is unintelligible unless we understand it as having elements of plurality, comparison, normativity and disputation, in the ways Kretchmar proposed. He began with his understanding of competition 'from the natural standpoint', drawing from his experiences of it, and it clearly contained the seeds of all he proceeded to unwrap in subsequent paragraphs, notably that competitions "require comparison"; from contestants who "lay claim to the higher position"; for "evaluating their similarities and differences"; to "see which one prevails" [2014, 23]. So, all the elements were there from the start.

\section{Conclusion}

The claimed elements of competition have been considered separately in order to evaluate Kretchmar's conclusion that "the elimination of any one of these elements plurality, comparison, normativity, or disputation - renders competition unintelligible" [2014:27]. My conclusion is that not only is competition intelligible without reference to any one of the four elements but that it is intelligible without reference to any of them. By way of conclusion I illustrate this latter position first with respect to the institutional and then with the participatory sense of competition.

Are the following claims intelligible? 
1. We took advice from experienced people, studied examples, and worked seriously to construct rules for our cycling competition. We made it clear that the judge's decision would be final, and based entirely on the order competitors crossed the finishing line, with the winner to be awarded first prize, the second over the line, second prize, and so on. Photographic evidence would be available if needed. We were sure that with the competition being decided by objective criteria alone there would be few if any disputes about who had won, and we clarified that we recognised ties mighty occur. In the event, only one competitor signed up and entered our competition.

Next, with respect to the participatory use of 'competition':

2. As instructed I entered my poem into the competition by post, not knowing the relative quality of other submissions. I had written the best I could, but had no confidence that I could write better than other people. Two weeks later I received a response from the organisers to say that because mine was the only entry they were unable to compare my poem with those of other entrants; unable therefore to come to a conclusion about the relative quality of my poem compared with that of any others; but that because I met all the competition rules, they would award me first prize.

It is the conclusion to this article that while omitting elements related respectively to the institutional and then to the participatory uses of competition, both examples are still intelligible.

\section{ACKNOWLEDGMENTS}

My thanks to members of the British Philosophy of Sport Association who commented on a shortened version of this paper at their annual conference in Eastbourne, April 2016, and to the anonymous reviewers for this journal who have stimulated me to add material which, I believe, has helped to strengthen my arguments.

\footnotetext{
Notes.

1 Such properties have been attributed to 'competition' for some time. It is possible to discern three of them in Coakley's [1994: 78] account that 'competition is a process through which 'winners' and 'losers' are identified and all people are ranked hierarchically on the basis of who does better than others in a particular field."

${ }^{2}$ Although my discussion here is of participants acting competitively towards each other, I recognise that someone can be a participant in a competition without having a competitive motive, a distinction used by Kleinig [1982: 164-165].

${ }^{3}$ Readers of Kretchmar [2014] will note that this is not where he begins his discussion. My reasons for so doing, however, should be clear by the end of this section. And oddly, after having discussed comparison, plurality and then normativity, he concludes [2014, 35] that the latter "can be identified as a second cornerstone of competition."
} 


\footnotetext{
${ }^{4}$ Plurality is far from an unusual or new suggestion in respect of giving an account of competition. See for example Dearden's three conditions [1972: 120-121]. However, such references to plurality need to be distinguished from that of Skultety [2011].

${ }^{5}$ See for example, in addition to his 2014 article, his chapter discussion in Morgan, W.J. [ed.] [2007] whose title incorporates reference to both contests and competition and where he discusses them as one and the same entity. I cannot locate in his writings, however, a defence of this practice.

${ }^{6}$ Kretchmar's understanding of normativity given here differs from that of others who also highlight 'competition' as a normative concept. See, for example, Fielding: 133-134.

${ }^{7}$ This is similar to the remark made by Caillois [1961: 15] that in competitive games, for the competitor, "the point of the game is to have his superiority in a given area recognized." But recall Dunlop's [1975] reply to the same point made by Bailey [1975]: "He [Bailey] seems to think that one can move from 'the point of the game is to win it' to 'the only reason why people play games is to show their superiority over others in the given area'. This, of course, is a quite illegitimate inference."

${ }^{8}$ But some claims appear to challenge this interpretation, e.g. "Winning, whatever else it may be, is a statement of superiority and dominance over others" [Russell, J.S. 2014: 240].

${ }^{9}$ My view is that the elements are linked in so far as a comparative evaluation depends upon comparison being possible, and if the latter is by and of competitors in competition, there must be at least two of them. Hence the third element [normativity] depends upon the second [comparison], and the second upon the first [plurality]. The fourth element, of disputation between competitors, all of whom maintain and want to demonstrate they are the best, is connected to the other three, but not in such a tight way. It is the competitors who make claim to their own superiority in the comparisons; hence the connection. But while the first three elements have conceptual connections [to each other: not to competition], whether and how competitors evaluate their relative strengths is, I insist and am about to discuss, a contingent matter.

${ }^{10}$ It is surely possible to regard the game of 'musical chairs' as a competition without attributing any merit to its performers or winner. It can be played for fun.

${ }^{11}$ Compare this with Dearden's $3^{\text {rd }}$ condition, namely that those in competition who know that their gaining what is desired would exclude the other[s] gaining it, nevertheless persist in striving to do so.

${ }^{12}$ I remain unclear on what Kretchmar understands here to be a dispute. I consider first the idea that it is open knowledge between those in a competition that each believes he is superior in the competitive event, and hence disagrees that others are able to demonstrate their superiority over him.

${ }^{13}$ Adopting an etymological approach, Dombrowski $[2012,37]$ denies the disputation element altogether. Replacing it with an interrogative one he says "'competition' literally means 'to ask with' one's opponent. The competitors are, in effect, asking each other the question, 'which of us is better at a certain activity?'”
}

\section{References}

BAILEY, C. 1975. Games, Winning and Education. Cambridge Journal of Education 5, 1, 40-50.

CAILLOIS, R. 1961. Man, Play and Game. New York: Free Press.

COAKLEY, J. J. 1994. Sport in Society: issues and controversies. [5 ${ }^{\text {th }}$ edn.] London: Mosby.

DEARDEN, R. F. 1972. Competition in Education. Journal of the Philosophy of Education 6, 4:119-133.

DOMBROWSKI, D.A. 2012. Homer, Competition, and Sport. . Journal of the Philosophy of Sport 39, I: 33-51.

DUNLOP, F. 1975. Bailey on Games, Winning and Education. Cambridge Journal of Education 5, 3, 153-160.

FIELDING, M. 1976. Against competition. Proceedings of the Philosophy of Education Society 10, July: $124-146$ 
HINDRIKS, F. 2012. Collective Acceptance and the Is-Ought Argument. Ethical Theory and Moral Practice, 16: 9353.

HUDSON, W D. [ed.] 1969. The is-ought Question: a collection of papers on the central problem in philosophy. London: The Macmillan Press.

KLEINIG, J. 1982. Philosophical Issues in Education. London: Routledge.

KRETCHMAR, S. and ELCOMBE, T. 2007. In Defense of Competition and Winning: Revisiting Athletic tests and Contests. In Ethics in Sport, ed. W.J. Morgan, 181-194. Champaign, III. Human Kinetics.

KRETCHMAR, S. 2012. Competition, Redemption, and Hope. Journal of the Philosophy of Sport 39, I: 101-116.

KRETCHMAR, S. 2014. A phenomenology of competition. Journal of the Philosophy of Sport 41, I: 2137.

ROYCE, R. J. 2013. Skultety's Categories of Competition - A competing Conceptualisation? Sport, Ethics and Philosophy 7, 2: 217-230.

RUSSELL, J. S. 2014. Competitive sport, moral development, and peace. In Bloomsbury companion to the philosophy of sport, ed. C. Torres, 228-244. London: Bloomsbury.

SKULTETY, S. 2011. Categories of Competition. Sport, Ethics and Philosophy 5, 4: 433-446.

SKULTETY, S. 2015. Revisiting Competitive Categories: A reply to Royce. Sport, Ethics and Philosophy 9, 1: 6-17. 